\title{
Virtual Prototyping Of Garments AND THEIR FIT TO THE BODY
}

\author{
JeVSniK, S.; PILAR, T.; STJEPANOVIC, Z . \& RUdOLF, A.
}

Abstract: Virtual prototyping of garments provides high potential for design, product development and marketing processes. Fit of a garment on the body model is an important factor to design comfortable, functional and well fitted garments. Today, the majority of CAD systems for garments' pattern design have 3D virtual garments simulation software for garment prototyping and fit evaluation. The garment is composed of 2D patterns and evaluation of the garment's fit is performed on the 3D human body model, where parametric mannequin or scanned human body represent a virtual body model. Based on the results of this study and many recent research works it can be assured that virtual prototyping is a promising technique that has a potential to replace conventional garments' prototyping. However, it can be successful only when all specific characteristics of the textile materials and accurate virtual body models to simulate the garment fit are fully taken into account.

Key words: virtual prototyping, simulation, 3D scanning, garments fit, body figure
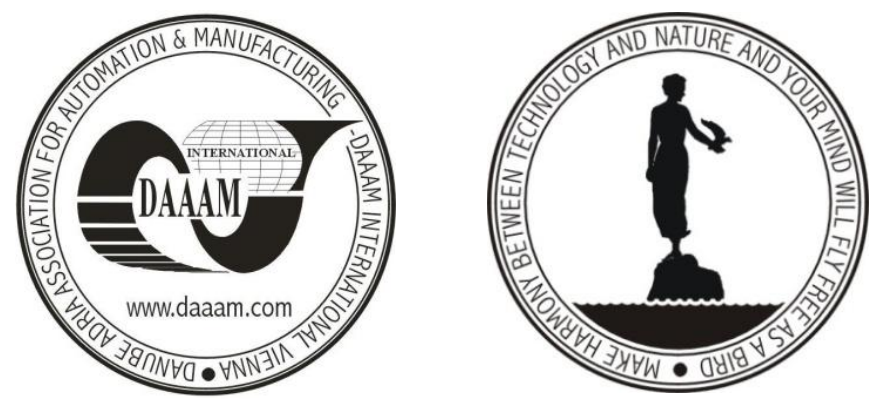

Authors' data: Assoc.Prof. Dr. Jevsnik, S[imona]*; M.Sc. Pilar, T[anja]**; Assoc.Prof. Dr. Stjepanovic, Z[oran]***; Assist.Prof. Dr. Rudolf, A[ndreja]***, *Academy of Design, Ljubljana, Slovenia, ** Ortum d.o.o., Ljubljana, Slovenia, ***University of Maribor, Faculty of Mechanical Engineering, Department of Textile Materials and Design, Maribor, Slovenia, simonajevsnik@gmail.com, tanjapilar@yahoo.com, stjepanovic@uni-mb.si, arudolf@uni-mb.si

This Publication has to be referred as: Jevsnik, S[imona]; Pilar, T[anja]; Stjepanovic, Z[oran]; Rudolf, A[ndreja] (2012). Virtual Prototyping of Garments and Their Fit to the Body, Chapter 50 in DAAAM International Scientific Book 2012, pp. 601-618, B. Katalinic (Ed.), Published by DAAAM International, ISBN 978-3901509-86-5, ISSN 1726-9687, Vienna, Austria

DOI: $10.2507 /$ daaam.scibook.2012.50 


\section{Introduction}

Virtual prototyping was developed with multiple aims stated (Umberto et al., 2008). Virtual prototyping is a technique in the process of garment development that involves application of computer aided design intended for garments development and virtual prototyping of them. Its aim is to integrate all specific characteristics of the garment into the virtual prototype that fits the virtual human body model. It is well-know that the body model used for virtual prototyping could be the parametric mannequin or scanned body model (Allen et al., 2003, Liu et al., 2010, Lee et al., 2007, Stjepanović et al., 2011). The CAD systems intended for garments' virtual prototyping usually offer parametric mannequins. In general, adjustment of their body dimensions is limited to the average body figure, which represents a problem when virtually prototyping the garments for nonstandard body figures. Therefore, in order to achieve more realistic garment simulation an investigation into the garment fit to different virtual body models (parametric and virtual) was performed due to comparison with real garment fit. In addition, evaluation procedure for assessment of the garment fit to body models was carried out in this study.

\section{Virtual Prototyping of Garments}

With application of the 3D virtual garment prototyping the garment's patterns can be placed and draped on the virtual human body. When the virtual prototyping is accurate the garment fit to the body model reflects and combines characteristics of the garment style, garment pattern design, virtual body model and mechanical properties of textiles (Jevšnik et al., 2009, Rudolf et al., 2010, Stjepanović et al., 2012). Indeed it can be mentioned that today a central focus of researches in this area obviously remains on development of the efficient mechanical simulation models, which can accurately reproduce the specific mechanical properties of textiles. The other aspect of the researches focuses on modelling of virtual humans to assure representation of the exact human body figure needed for virtual prototyping.

\subsection{Simulation of specific mechanical properties of fabrics}

The main objective of garment simulation is to develop the efficient mechanical simulation model, which can accurately reproduce the specific mechanical properties of the fabric. Numerous fabric simulation methods are not sufficient for designing and prototyping of garments. They should provide to pattern designers a tool for performing garment creation with high-level interaction, and testing of the fit and drape of the garment, as well as adjusting the shape of the patterns, same as this allows the conventional development of garments (Volino et al., 2005, MagnenatThalmann \& Volino, 2005).

Textile material is by nature highly deformable and specific simulation problems arise from this fact. Therefore, mechanical representation should be accurate enough to deal with the nonlinearities and large deformations that occur in fabric, e.g. folds, and wrinkles (Volino et al., 2005). 
The existing approaches for fabric modelling are classified into three categories; these are geometric, physical and hybrid techniques. Geometric methods apply geometrical equations to perform visualization of fabric without considering the physical properties of the fabric (Weil, 1986). Physically based models represent fabric as a collection of numerous tiny elements where forces or energies associated with each element are calculated to simulate the behaviour of fabric. Physically based modelling methods include finite element models (Terzopoulos et al., 1987, Collier et al., 1991, Chen \& Govindaraj 1995, Gan et al., 1995, Ascough et al., 1996), finite volume models (Hu \& Chen, 2000) and particle system models (Breen et al., 1994, Provot, 1995, Eberhardt et al., 1996, Dai et al., 2003, Ji1, 2006. Among these models the particle system models offer the easiest way to perform fabric simulation. Particle systems consider the fabric to be represented only by the set of vertices that constitute the polygonal mesh of the surface (Magnenat-Thalmann \& Volino, 2005). These particles move according to action of forces that represent the mechanical behaviour of the fabric. Among different variations of particle systems, the spring-mass model is the simplest and most widely used. It considers the distance between neighbouring particle pairs as the only deformation measurement and interaction source representing the internal elasticity of the cloth (Magnenat-Thalmann \& Volino, 2005). The well-known are also hybrid techniques, used mostly to implement more complex simulation models. They combine physical and geometrical methods (Lafleur et al. 1991, Yang \& Thalmann, 1993, Volino \& Thalmann, 1994, Baraff \& Witkin, 1998). Furthermore, numerical integration methods, and collision detection and response are involved when virtually simulating the garments (Volino \& Magnenat-Thalmann, 2005, Volino, et al., 2005).

The mechanical behaviour of fabrics is usually measured using special measuring systems, such as KES (Kawabata Measuring System) and FAST (Fabric Assurance by Simple Testing), which measure tensile, shear, bending, compression and surface properties of the fabrics. Depending on the complexity of the computation system, the mechanical properties that are mainly responsible for the fabric behaviour were investigated by (Luible \& Thalmann-Magnenat, 2007). They found out that KES-F measurements provide complete strain-stress profiles and, therefore, allow the assessment of the nonlinearity of fabric parameters, while FAST measurements permits only the linear interpretation of the measured data. The efficiency of the garments' virtual prototyping described in this contribution was researched on the basis of comparison between women's jackets where (a) all pattern pieces were described by mechanical properties of the fabrics and (b) some pattern pieces were described by mechanical characteristics of the fused panels (collar, lapel, front part) measured by FAST measuring system (Rudolf et al., 2008). It has been shown that for achieving the realistic virtual garment simulation the mechanical properties of the fused panels need to be included in the simulation.

\subsection{Simulation of virtual humans}

With the advance of 3D scanning techniques, the individualized human body can be easily captured and modelled with a mesh model (Allen et al., 2003, Liu et al., 2010). In addition, the geometric definition of the human body model was necessary 
to use semantic features to facilitate the garment design on the virtual body model. The segmentation of human body model leaded to a natural parameterization of the model with the aim to perform accurate measurement of the individual scanned body model and to use these measurements to adjust the parametric virtual body model in 3D CAD systems.

Human body modelling is a challenging problem with a wide range of applications from virtual surgery to animation in feature movies (MagnenatThalmann \& Thalmann, 2005). Three-dimensional body model is vital for the virtual try-on system and has a strong impact on complexity and effect of a garment simulation. Therefore, the study of 3D body modelling has a great potential in both research and application. Nowadays, with the aid of laser scanners it is easy to obtain the 3D information of the individual body in the form of point clouds. Various techniques have been proposed to reconstruct model from noised point cloud. Notably, the techniques can be typically classified as three types: implicit, parametric and triangulation methods (Liu et al., 2010). The scanned and carefully reconstructed body model provides a realistic 3D body representation that could be imported into the 3D CAD system for garments virtual prototyping. Research on the garment fit and sportswear for professional purposes, respectively, to the parametric body model and scanned 3D body model showed significant differences between virtual garments' fits to body models and successfulness of virtual prototyping using the scanned 3D body model (Stjepanovič et al., 2010, Stjepanovič et al., 2011).

\section{Garment fit on the body model}

Garment fit is regarded as the most important element to customers in clothing appearance. There are many definitions of the garment fit. One of them is 'Clothing that fits well, conforms to the human body and has adequate ease of movement, has no wrinkles and has been cut and manipulated in such a way that it appears to be part of the wearer" (Yu, 2004 ). The fit of a garment depends on the selected construction system for pattern design (Gregorčič et al. 2011).

Evaluation of the garment fit is usually performed using the fit evaluation scale.

Fitting in the real world can be reflected in cyber space for 3D virtual fitting simulation technology to be used by the tool for fit estimating (Lee et al., 2007).

Since the virtual cloth simulation received much attention in the past decade, and the fashion industry has been attracted to use this newly available tool for product development process, the most of researches in this area focuses into the comparison of the garment fit to the real and virtual body model and parametric mannequin of the used 3D CAD system, respectively (Wu et al. 2011). Another approach of the virtual garment fit evaluation was to investigate the influence of the mechanical and structural parameters of the fabrics on strain distribution in garment and distance ease between garment and parametric mannequin of the used 3D CAD system (Ancutienè \& Sinkevičiūtè, 2011, Rudolf et al. 2012). None of these studies on the virtual garment fit by using the commercial 3D CAD systems for simulation of garments addressed the evaluation of the virtual garment fit to the scanned 3D body model and their comparison with the real and parametric body model. 


\section{Study of the influence of the garment fit to different body models}

The study focuses on the research of garments fit on the body. The purpose was to identify differences between the conventional and virtual garment prototyping process. The real body model, parametric and scanned 3D body models were used for comparison of the real and virtual garments on the basis of the criteria for assessing the fit of clothing to different body models.

The research was conducted in three stages:

(a) Selection of the women jackets' styles, and fabrics and fusible interlinings for their production. The process of computer jackets pattern design for the body figure of the garment size 42 was carried out using the OptiTex CAD system.

(b) Conventional and virtual garment prototyping. The results of the conventional prototyping were the real produced women's jackets that were tested on the real body model. The results of the virtual prototyping were the virtual jackets that were tested on two virtual body models (parametric 3D body model and scanned 3D body model). Virtual prototyping was performed by using the OptiTex CAD system and based on the measured mechanical parameters of the fabrics and fused panels by using the FAST measuring system. The appropriate appearance (colour, texture) of the virtual textiles and jackets, respectively, was achieved by scanning the woven textile fabrics.

(c) Evaluation of the jacket prototypes fit to the real, parametric and scanned body models depending on the mechanical properties of the fabrics used for in this study.

\subsection{Styles of the women jackets and used materials}

The drawings of the styles of women's jackets (Nika, Lida, Mia) are represented in Tab. 1. They were made from fabrics suitable for upper garments composed of different natural (cotton, linen) and synthetic fibres (polyamide); some fabric contained 2-3\% elastic yarns. Each style of the jacket was made up from two different fabrics. Basic properties of the used fabrics are collected in Tab. 1.

In addition, front parts of the jackets, collars and lapels were fused. Fusing was performed for all models using the same type of fusible interlinings of Lainiere de Picardie and Mayer fusing machine. Fusible interlining had following characteristics: basic textile material of $100 \%$ polyester, thermoplastic adhesive of $100 \%$ polyamide, thermoplastic adhesive quantity of 23 meshes and surface mass of fusible interlining of $35 \mathrm{gm}^{-2}$.

\subsection{Determination of the low-stress mechanical parameters for jackets simulation}

Low-stress mechanical parameters (tensile, bending, shear, surface thickness) of the fabrics and fused panels were measured by using the FAST measuring system in order to obtain the realistic virtual jackets' prototypes, Tabs. 2 and 3. Determined mechanical properties of the fabrics and fused panels were converted by using the Fabric Converter programme of the OptiTex CAD system. 


\begin{tabular}{|c|c|c|c|c|c|c|}
\hline \multirow{2}{*}{\multicolumn{2}{|c|}{$\begin{array}{l}\text { Name and drawings of the } \\
\text { jackets' styles }\end{array}$}} & \multirow[b]{2}{*}{ Fabric code } & \multirow{2}{*}{$\begin{array}{c}\text { Fabric } \\
\text { composition } \\
(\%)\end{array}$} & \multicolumn{2}{|c|}{ Yarn density } & \multirow{2}{*}{$\begin{array}{c}\text { Surface } \\
\text { mass } \\
\left(\mathrm{g} / \mathbf{m}^{2}\right) \\
\end{array}$} \\
\hline & & & & $\begin{array}{c}\text { Warp } \\
\text { (yarns/cm) }\end{array}$ & $\begin{array}{c}\text { Weft } \\
\text { (yarns/cm) }\end{array}$ & \\
\hline \multirow{2}{*}{ 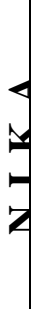 } & & TK-1Z & $\begin{array}{c}85 \% \text { linen } \\
15 \% \text { polyamide }\end{array}$ & 42 & 23.5 & 109 \\
\hline & & TK-1Č & $\begin{array}{c}85 \% \text { linen } \\
15 \% \text { polyamide }\end{array}$ & 42 & 23.5 & 113 \\
\hline & \multirow{2}{*}{$\mathbb{N}$} & TK-2M & $\begin{array}{l}98 \% \text { cotton } \\
2 \% \text { elastane }\end{array}$ & 85 & 34.0 & 200 \\
\hline & & TK-2Č & $\begin{array}{l}98 \% \text { cotton } \\
2 \% \text { elastane }\end{array}$ & 84 & 33.5 & 164 \\
\hline & & TK-4B & $\begin{array}{l}97 \% \text { cotton } \\
3 \% \text { elastane }\end{array}$ & 63 & 29.0 & 184 \\
\hline & & TK-4M & $\begin{array}{l}97 \% \text { cotton } \\
3 \% \text { elastane }\end{array}$ & 58 & 28.5 & 182 \\
\hline
\end{tabular}

Tab. 1. Styles of the women's jackets and basic properties of the fabrics

\begin{tabular}{|c|c|c|c|c|c|c|c|}
\hline \multirow[t]{2}{*}{$\begin{array}{l}\text { Fabric } \\
\text { code }\end{array}$} & \multicolumn{2}{|c|}{$\begin{array}{c}\text { Extension at load of } \\
98.1 \mathrm{Nm}^{-1} \\
(\mathrm{E} 100 / \%) \\
\end{array}$} & \multicolumn{2}{|c|}{$\begin{array}{l}\text { Bending rigidity } \\
\qquad(\mathrm{B} / \mu \mathrm{Nm})\end{array}$} & \multirow{2}{*}{$\begin{array}{c}\text { Shear } \\
\text { rigidity } \\
\left(\mathrm{G} / \mathrm{Nm}^{-1}\right)\end{array}$} & \multirow{2}{*}{$\begin{array}{c}\text { Surface } \\
\text { thickness } \\
(\mathrm{ST} / \mathrm{mm})\end{array}$} & \multirow{2}{*}{$\begin{array}{c}\text { Surface } \\
\text { mass } \\
\left(\mathrm{W} / \mathrm{gm}^{-2}\right)\end{array}$} \\
\hline & Warp & Weft & Warp & Weft & & & \\
\hline TK-1Z & 2.0 & 2.1 & 2.6 & 14.3 & 12.7 & 0.194 & 109 \\
\hline TK-1Č & 2.6 & 2.2 & 3.0 & 16.2 & 11.5 & 0.179 & 113 \\
\hline TK-2M & 1.4 & 3.9 & 11.9 & 6.1 & 46.4 & 0.147 & 200 \\
\hline TK-2Č & 1.9 & 3.5 & 9.4 & 4.7 & 48.2 & 0.145 & 164 \\
\hline TK-4B & 1.6 & 13.3 & 20.5 & 6.9 & 121.0 & 0.229 & 184 \\
\hline TK-4M & 1.9 & 14.7 & 20.4 & 7.4 & 129.0 & 0.233 & 182 \\
\hline
\end{tabular}

Tab. 2. Low-stress mechanical parameters of the fabrics

\begin{tabular}{|c|c|c|c|c|c|c|c|}
\hline \multirow{2}{*}{$\begin{array}{c}\text { Fused } \\
\text { panel code }\end{array}$} & $\begin{array}{c}\text { Extension at load of } \\
98.1 \mathrm{Nm}^{-1} \\
(\mathrm{E} 100 / \%)\end{array}$ & \multicolumn{2}{|c|}{$\begin{array}{c}\text { Bending rigidity } \\
(\mathrm{B} / \mu \mathrm{Nm})\end{array}$} & $\begin{array}{c}\text { Shear } \\
\text { rigidity } \\
\left(\mathrm{G} / \mathrm{Nm}^{-1}\right)\end{array}$ & $\begin{array}{c}\text { Surface } \\
\text { thickness } \\
(\mathrm{ST} / \mathrm{mm})\end{array}$ & $\begin{array}{c}\text { Surface } \\
\text { mass } \\
\left(\mathrm{W} / \mathrm{gm}^{-2}\right)\end{array}$ \\
\cline { 2 - 5 } TK-1Z-M & 1.3 & 1.6 & 42.18 & 55.2 & 101.2 & 0.225 & 135 \\
\hline TK-1Č-M & 1.1 & 1.8 & 32.5 & 59.0 & 99.9 & 0.201 & 134 \\
\hline TK-2M-M & 1.3 & 2.5 & 55.0 & 54.1 & 112.4 & 0.201 & 225 \\
\hline TK-2Č-M & 1.2 & 2.2 & 25.2 & 45.1 & 123.6 & 0.198 & 188 \\
\hline TK-4B-M & 1.1 & 9.8 & 60.7 & 47.0 & 236.7 & 0.276 & 206 \\
\hline TK-4M-M & 1.3 & 10.0 & 66.1 & 51.1 & 223.5 & 0.285 & 210 \\
\hline
\end{tabular}

Tab. 3. Low-stress mechanical parameters of the fused panels 


\subsection{Preparing the virtual body models}

In this study the parametric 3D body model was obtained by using the OptiTex PDS programme based on the body measures determined by the 3D body scanner. These body measures were: body height, neck, bust, overbust and underbust, waist, hips, upper arm, wrist, thigh and high thigh, knee, and ankle circumferences, neck, arms, waist to hips, waist to floor and inseam lengths, and many others with the aim to achieve more realistic appearance of the virtual body model.

Scanning of the selected female was performed by using the 3D body scanner Vitus Smart and ScanWorx V 2.7.2 programme package at the Faculty of Textile Technology, University of Zagreb, Croatia. The process of generation of scanned 3D female body model involved the body reconstruction. Namely, 3D scanner cannot produce sufficient scan data, which results in defected female body model. For this reason the reconstruction of the scanned 3D female body model was performed by using the Atos, Blender, Rhino 4, Netfabb and MeshLab programs (Stjepanović et al., 2010). The scanned and reconstructed 3D body model was imported into the OptiTex PDS programme for the simulation of virtual women's jackets.

A deviation between the parametric 3D body model and scanned/reconstructed $3 \mathrm{D}$ body model of the selected female was achieved, especially, when observing the scanned body posture, as can be seen in Fig. 1 (Stjepanović et al., 2010).

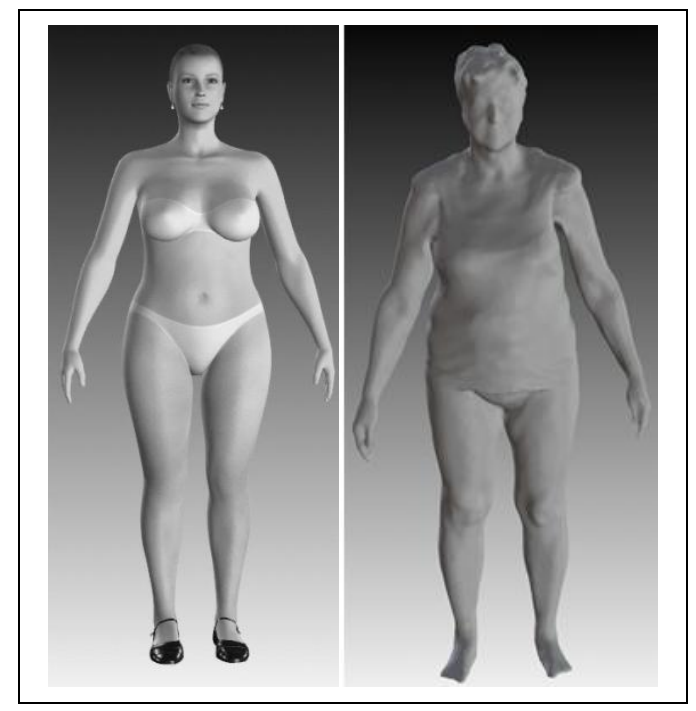

(a)

(b)

Fig. 1. Female virtual body model (a) parametric 3D body model, (b) scanned and reconstructed $3 \mathrm{D}$ body model

\subsection{Evaluation of the jackets' fit to different body models}

Evaluation of the jackets' fit to body models was performed by assessing the fit of jackets' prototypes on a real body model, virtual parametric 3D body model and virtual scanned 3D body model. Next, a procedure for evaluation of the fit of real and virtual jackets prototypes to the body models was developed. For this purpose, specific areas were defined on the jacket, Fig. 2, according to which the front, side and back views were observed and evaluated. 
The evaluation procedure is suitable for assessment of both real and virtual models and includes the following steps (Pilar, 2012):

- Selection of the jacket style.

- Selection of the evaluation area on the jacket.

- Assessment of a jacket fit to the body model using the following criteria grades: 1 (good), 0 (satisfactory) and -1 (inappropriate).

The following are presented the evaluation areas and criteria for front, back and side views of the jacket, Tab. 4.

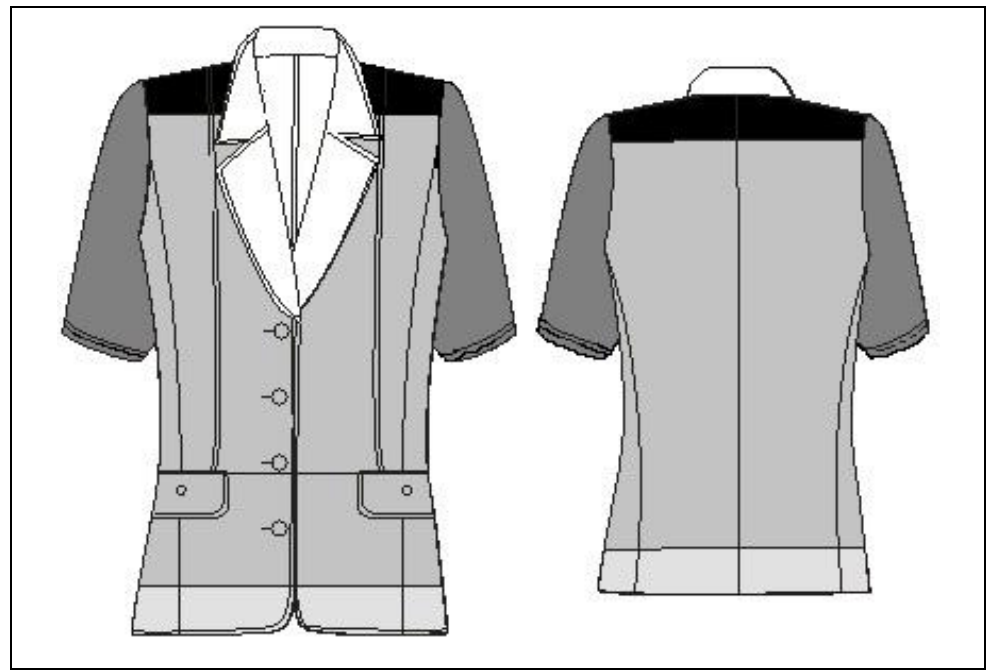

Fig. 2. Five evaluation areas (coloured) of jacket (front and back views) (Pilar, 2012)

\begin{tabular}{|c|c|c|c|c|}
\hline $\begin{array}{c}\text { Jacket } \\
\text { area }\end{array}$ & \begin{tabular}{|l} 
Evaluation \\
area
\end{tabular} & Area definition & Criteria description & Grade \\
\hline \multirow{5}{*}{$\begin{array}{l}F \\
Z \\
0 \\
0 \\
\simeq\end{array}$} & $\begin{array}{l}\text { Bust and } \\
\text { hips }\end{array}$ & $\begin{array}{l}15 \mathrm{~cm} \text { above the bust } \\
\text { line and up to } 5 \mathrm{~cm} \\
\text { above the jacket edge. }\end{array}$ & $\begin{array}{l}\text { Jacket fit to the body shape: } \\
\text { - Jacket fits the body shape } \\
\text { - Slight wrinkling of fabrics due to the body shape } \\
\text { - Strong longitudinal or transverse wrinkles }\end{array}$ & $\begin{array}{c}1 \\
0 \\
-1\end{array}$ \\
\hline & Shoulder & $\begin{array}{l}\text { Shoulder area and } 10 \mathrm{~cm} \\
\text { below the shoulder on } \\
\text { the front part. }\end{array}$ & $\begin{array}{l}\text { Jacket fit to the shoulders: } \\
\text { - Just enough long shoulder } \\
\text { - Slight wrinkling in the shoulder area } \\
\text { - Too long shoulders; strong wrinkling in the shoulder area }\end{array}$ & $\begin{array}{r}1 \\
0 \\
-1\end{array}$ \\
\hline & Sleeve & The whole sleeve. & $\begin{array}{l}\text { Sleeve fit to the body: } \\
\text { - Great appearance of the sleeve } \\
\text { - Slight wrinkling of the sleeve } \\
\text { - Shift of the sleeve and wrinkling } \\
\end{array}$ & $\begin{array}{r}1 \\
0 \\
-1\end{array}$ \\
\hline & $\begin{array}{l}\text { Collar and } \\
\text { lapels }\end{array}$ & $\begin{array}{l}\text { The whole collar and } \\
\text { lapels. }\end{array}$ & $\begin{array}{l}\text { Collar and lapels fit to the body: } \\
\text { - Smoothly lies on the front part } \\
\text { - Slightly deviates from jacket } \\
\text { - Turning up, tightening and wrinkling }\end{array}$ & $\begin{array}{r}1 \\
0 \\
-1\end{array}$ \\
\hline & Bottom edge & $\begin{array}{l}\text { The whole bottom edge } \\
\text { of jacket }(5 \mathrm{~cm}) .\end{array}$ & $\begin{array}{l}\text { Bottom edge fit to the body: } \\
\text { - Clean straight line of the bottom edge } \\
\text { - Slightly restless bottom edge } \\
\text { - Bottom edge weaves }\end{array}$ & $\begin{array}{r}1 \\
0 \\
-1\end{array}$ \\
\hline \multirow{2}{*}{$\begin{array}{l}\checkmark \\
u \\
\square \\
0\end{array}$} & $\begin{array}{l}\text { Back and } \\
\text { hips }\end{array}$ & $\begin{array}{l}5 \mathrm{~cm} \text { below the } \\
\text { shoulders and up to } 5 \mathrm{~cm} \\
\text { above the bottom edge. }\end{array}$ & $\begin{array}{l}\text { Jacket fit to the body shape: } \\
\text { - Jacket fits the body shape } \\
\text { - Slight wrinkling of fabrics due to the body shape } \\
\text { - Strong longitudinal or transverse }\end{array}$ & $\begin{array}{r}1 \\
0 \\
-1\end{array}$ \\
\hline & Shoulder & $\begin{array}{l}\text { Shoulders and } 5 \mathrm{~cm} \\
\text { bellow the shoulder. }\end{array}$ & $\begin{array}{l}\text { Jacket fit to the shoulders: } \\
\text { - Just enough long shoulder } \\
\text { - Slight wrinkling in the shoulder area } \\
\text { - Too long shoulders; strong wrinkling in the shoulder area }\end{array}$ & $\begin{array}{r}1 \\
0 \\
-1\end{array}$ \\
\hline
\end{tabular}




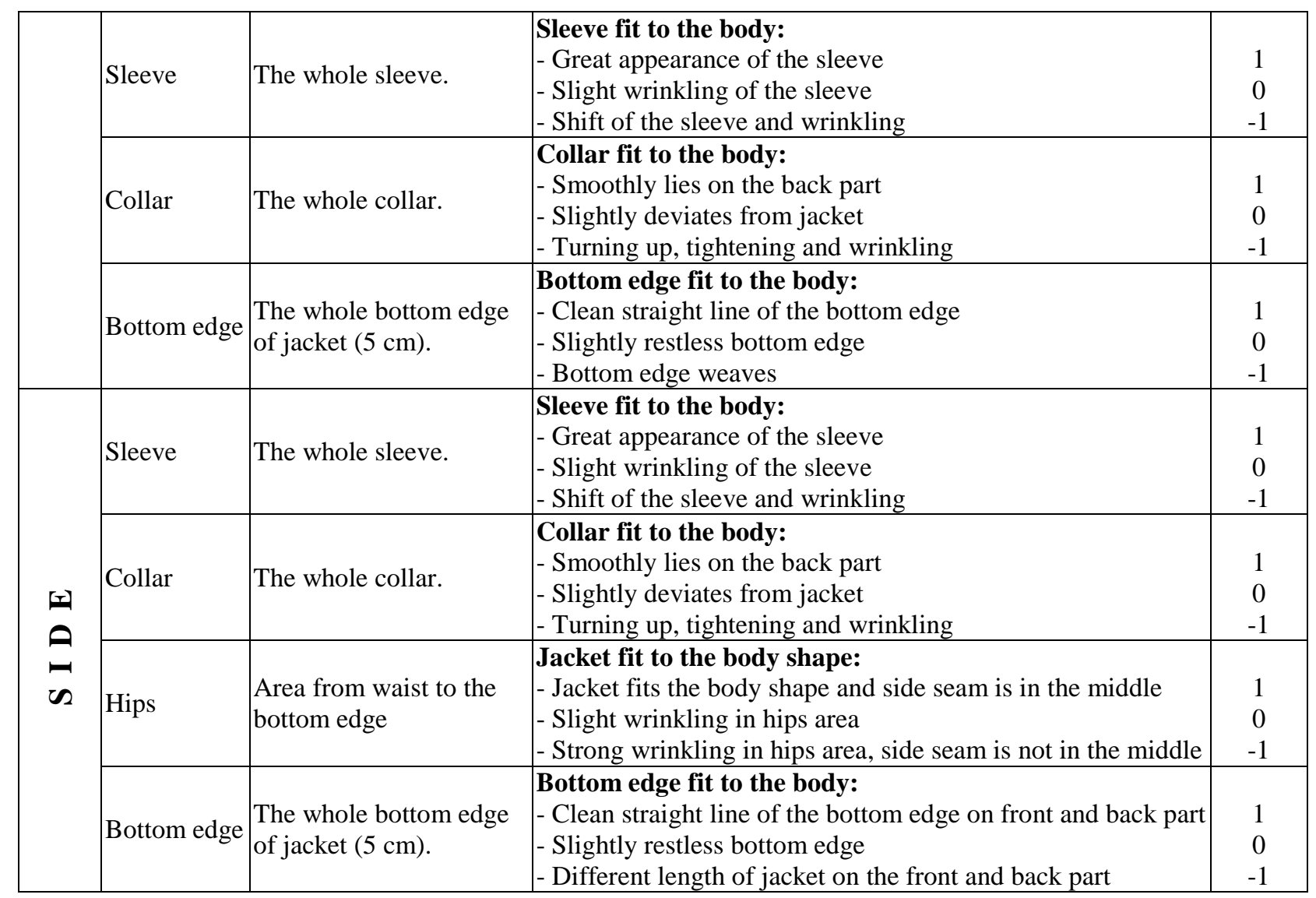

Tab. 4. The evaluation areas and criteria for the jacket (Pilar, 2012)

The evaluation of the jackets' fit to the body models was carried out by a group of 16 experts from the wider area of clothing engineering.

\section{Results and discussion}

In this study, the research results of clothing fit on the real body and on the virtual body models (3D scanned and parametric models), are given in the form of:

- Graphical representation of jackets fit to all body models from front and back views, as well as side view. The virtual body models were imported into the OptiTex PDS program for virtual garments' simulation. With the help of this program the virtual prototyping of jackets was carried out based on real measured mechanical properties of the fabrics and fused panels, Tabs. 2 and 3.

- Analyses of the jackets fit to the body models according to defined evaluation areas, and assessment criteria, which are given in Tab. 4. Altogether 14 areas related to three views of jackets were evaluated. Assessment of the jackets' fit to the body models is given for the real body model, scanned 3D body model and parametric 3D body model.

- The influence of mechanical properties of fabrics and fused panels on fitting of the jackets to body models due to defined evaluation areas and assessment criteria.

\subsection{Real and virtual prototypes of the jackets}

The real and virtual prototypes of the jackets and theirs fit to different body models are represented in Figs. 3 and 4. In these figures the fitting results are 
Jevsnik, S.; Pilar, T.; Stjepanovic, Z. \& Rudolf, A.: Virtual Prototyping of Garments and Their Fi...

presented for the jacket model Nika, which was produced from two different fabrics with codes TK-1Z and TK-1 Č. Styles Lida and Mia made up from different fabrics were represented in the same way; style Lida was produced using fabrics coded TK-

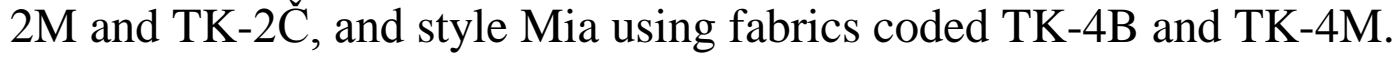

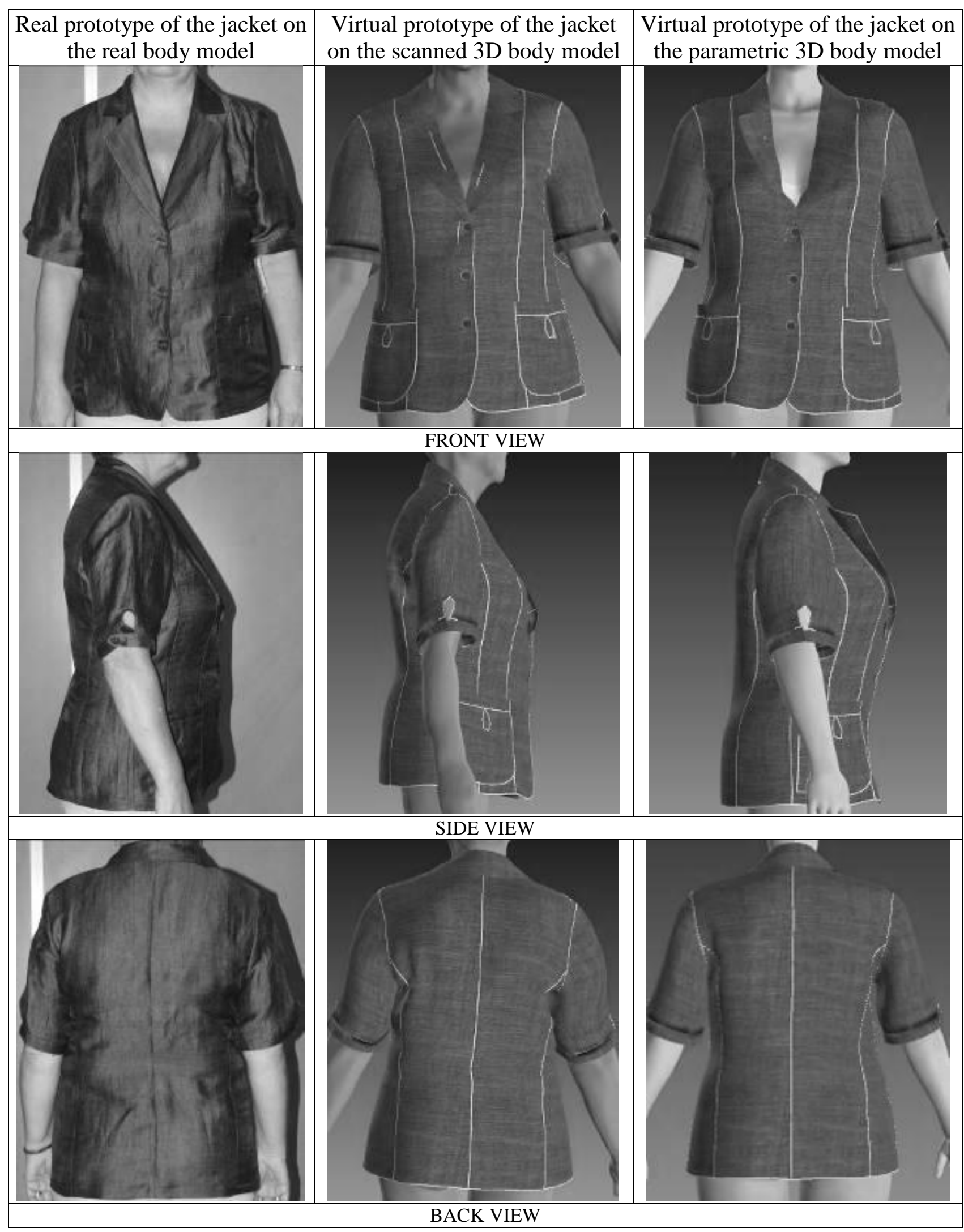

Fig. 3. Fitting results for the jacket's style Nika made up of fabric coded TK-1Z 


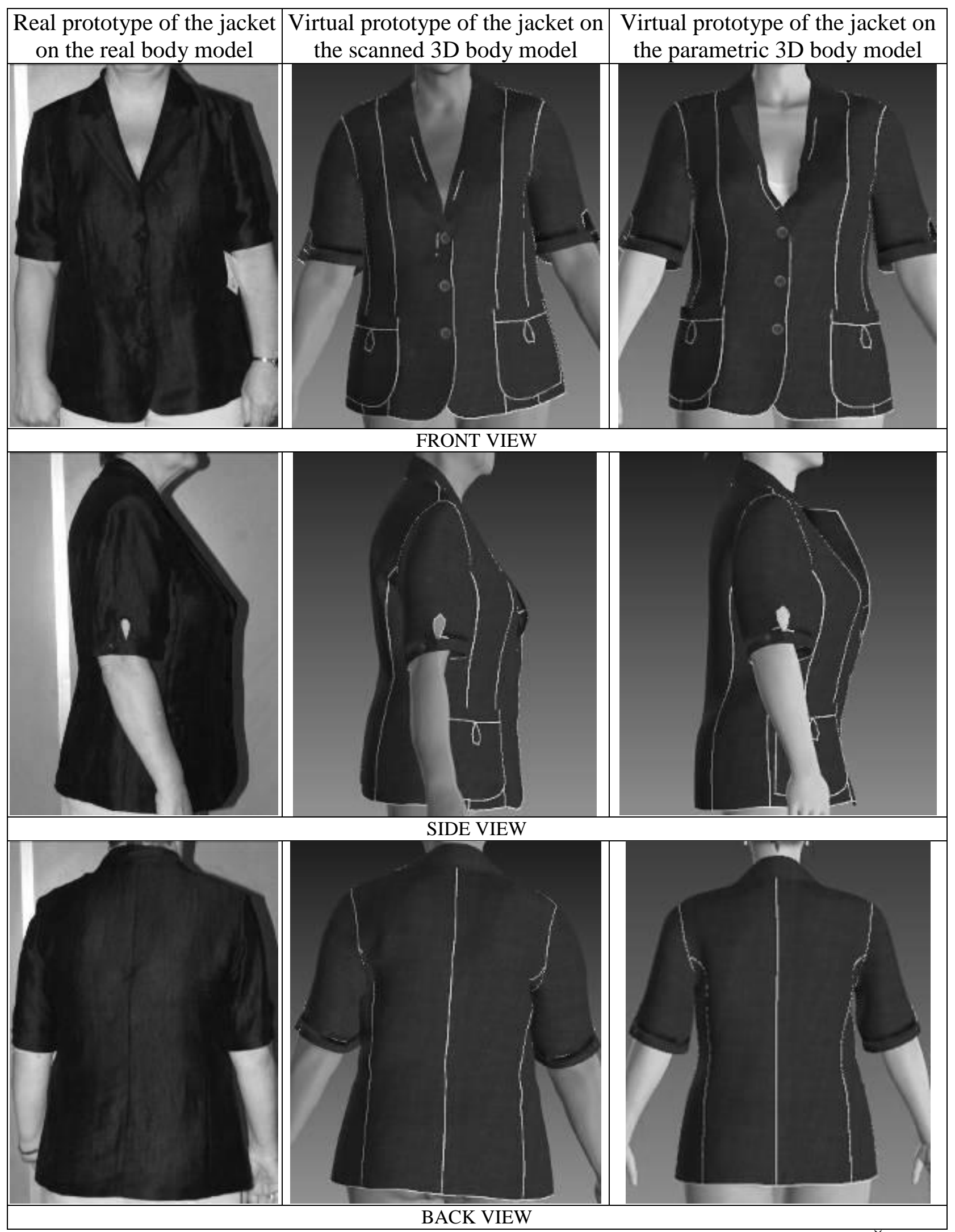

Fig. 4: Fitting results for the jacket's style Nika made up of fabric coded TK-1Č

The jacket style Nika had fused the front parts, lapels and collar with the fusible interlining. The jacket style Lida had also fused the front parts, lapel and collar of the jacket, while the jacket style Mia had fused the front parts, lapel, collar and pocket covers. 


\subsection{Assessment of the jackets' fit to the real and virtual body models}

The results of the fit estimation of the jackets' prototypes to different body models for defined evaluation areas are collected in Tabs. 5-7. Analysed were all jackets styles on the real body model and afterwards on the virtual parametric 3D body model and scanned 3D body model.

In the research, large discrepancies were found between jackets' fit to the virtual parametric and scanned body models. Those variations were smaller between realmade prototypes and 3D jackets prototypes on the scanned body model. Therefore, it can be concluded that capture of three-dimensional body figure and body size extraction is very important for the $3 \mathrm{D}$ representation of garments prototypes in a virtual environment.

\begin{tabular}{|c|c|c|c|c|c|c|c|c|c|c|c|c|c|c|c|c|c|c|c|}
\hline \multirow{3}{*}{\multicolumn{2}{|c|}{ Evaluation area }} & \multirow{2}{*}{\multicolumn{3}{|c|}{$\frac{\text { Jacket NIKA-1Z }}{\text { Grade }}$}} & \multirow{2}{*}{\multicolumn{3}{|c|}{\begin{tabular}{|c|} 
Jacket NIKA-1Č \\
Grade
\end{tabular}}} & \multirow{2}{*}{\multicolumn{3}{|c|}{\begin{tabular}{|c|} 
Jacket LIDA-2M \\
Grade
\end{tabular}}} & \multirow{2}{*}{\multicolumn{3}{|c|}{\begin{tabular}{|c|} 
Jacket LIDA-2Č \\
Grade \\
\end{tabular}}} & \multirow{2}{*}{\multicolumn{3}{|c|}{$\frac{\text { Jacket MIA-4B }}{\text { Grade }}$}} & \multirow{2}{*}{\multicolumn{3}{|c|}{$\frac{\text { Jacket MIA-4M }}{\text { Grade }}$}} \\
\hline & & & & & & & & & & & & & & & & & & & \\
\hline & & -1 & 0 & 1 & -1 & 0 & 1 & -1 & 0 & 1 & -1 & 0 & 1 & -1 & 0 & 1 & -1 & 0 & 1 \\
\hline \multirow{5}{*}{ 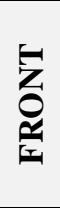 } & Bust area & 3 & 9 & 4 & 2 & 10 & 4 & 0 & 9 & 7 & 3 & 11 & 2 & 8 & 8 & 0 & 6 & 10 & 0 \\
\hline & Shoulder & 5 & 7 & 4 & 0 & 12 & 4 & 0 & 7 & 9 & 0 & 6 & 10 & 2 & 11 & 3 & 5 & 9 & 2 \\
\hline & Sleeve & 3 & 11 & 2 & 0 & 10 & 6 & 0 & 4 & 12 & 2 & 9 & 5 & 3 & 10 & 3 & 8 & 8 & 0 \\
\hline & Collar and lapel & 1 & 2 & 13 & 0 & 4 & 12 & 0 & 2 & 14 & 0 & 3 & 13 & 2 & 7 & 7 & 4 & 6 & 6 \\
\hline & Bottom edge & 5 & 7 & 4 & 8 & 6 & 2 & 0 & 8 & 8 & 2 & 10 & 4 & 0 & 9 & 7 & 4 & 10 & 2 \\
\hline \multirow{5}{*}{$\underset{\infty}{U}$} & Back area & 5 & 10 & 1 & 5 & 7 & 4 & 5 & 10 & 1 & 6 & 8 & 2 & 7 & 8 & 1 & 6 & 8 & 2 \\
\hline & Shoulder & 4 & 4 & 8 & 2 & 9 & 5 & 3 & 8 & 5 & 1 & 9 & 6 & 3 & 10 & 3 & 2 & 8 & 6 \\
\hline & \begin{tabular}{|l|} 
Sleeve \\
\end{tabular} & 4 & 10 & 2 & 6 & 8 & 2 & 5 & 9 & 2 & 3 & 9 & 4 & 7 & 8 & 1 & 7 & 8 & 1 \\
\hline & Collar & 1 & 5 & 10 & 0 & 6 & 10 & 1 & 6 & 9 & 0 & 3 & 13 & 1 & 3 & 12 & 3 & 3 & 10 \\
\hline & Bottom edge & 1 & 8 & 7 & 2 & 8 & 6 & 2 & 5 & 9 & 1 & 7 & 8 & 1 & 8 & 7 & 0 & 4 & 12 \\
\hline \multirow{4}{*}{ 䆟 } & Sleeve and shoulder & 7 & 8 & 1 & 5 & 5 & 6 & 1 & 10 & 5 & 2 & 7 & 7 & 3 & 9 & 4 & 6 & 8 & 2 \\
\hline & Collar & 2 & 4 & 10 & 1 & 4 & 11 & 1 & 1 & 14 & 1 & 6 & 9 & 2 & 8 & 6 & 0 & 8 & 8 \\
\hline & Hips & 2 & 5 & 9 & 2 & 4 & 10 & 2 & 10 & 4 & 1 & 10 & 5 & 2 & 9 & 5 & 0 & 12 & 4 \\
\hline & Bottom edge & 5 & 8 & 3 & 5 & 7 & 4 & 3 & 7 & 6 & 2 & 8 & 6 & 0 & 5 & 11 & 0 & 7 & 9 \\
\hline
\end{tabular}

Tab. 5.Assessment of fit for individual areas of jackets prototypes on the real body model

\begin{tabular}{|c|c|c|c|c|c|c|c|c|c|c|c|c|c|c|c|c|c|c|c|}
\hline \multirow{3}{*}{\multicolumn{2}{|c|}{ Evaluation area }} & \multirow{2}{*}{\multicolumn{3}{|c|}{\begin{tabular}{|c|} 
Jacket NIKA-1Z \\
Grade
\end{tabular}}} & \multirow{2}{*}{\multicolumn{3}{|c|}{\begin{tabular}{|l|} 
Jacket NIKA-1Č \\
Grade
\end{tabular}}} & \multirow{2}{*}{\multicolumn{3}{|c|}{$\begin{array}{l}\text { Jacket LIDA-2M } \\
\text { Grade }\end{array}$}} & \multirow{2}{*}{\multicolumn{3}{|c|}{\begin{tabular}{|l|} 
Jacket LIDA-2Č \\
Grade \\
\end{tabular}}} & \multirow{2}{*}{\multicolumn{3}{|c|}{\begin{tabular}{l|} 
Jacket MIA-4B \\
Grade \\
\end{tabular}}} & \multirow{2}{*}{\multicolumn{3}{|c|}{\begin{tabular}{|l} 
Jacket MIA-4M \\
Grade
\end{tabular}}} \\
\hline & & & & & & & & & & & & & & & & & & & \\
\hline & & -1 & 0 & 1 & -1 & 0 & 1 & -1 & 0 & 1 & -1 & 0 & 1 & -1 & 0 & 1 & -1 & 0 & 1 \\
\hline \multirow{5}{*}{ 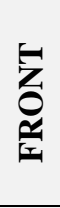 } & Bust area & 0 & 4 & 12 & 0 & 7 & 9 & 1 & 9 & 6 & 2 & 6 & 8 & 0 & 7 & 9 & 1 & 4 & 11 \\
\hline & Shoulder & 1 & 8 & 7 & 1 & 4 & 11 & 1 & 4 & 11 & 3 & 3 & 10 & 1 & 3 & 12 & 2 & 3 & 11 \\
\hline & \begin{tabular}{|l|} 
Sleeve \\
\end{tabular} & 3 & 5 & 8 & 1 & 10 & 5 & 1 & 8 & 7 & 4 & 5 & 7 & 2 & 4 & 10 & 2 & 4 & 10 \\
\hline & Collar and lapel & 1 & 2 & 13 & 2 & 2 & 12 & 1 & 2 & 13 & 0 & 2 & 14 & 1 & 5 & 10 & 1 & 4 & 11 \\
\hline & Bottom edge & 3 & 9 & 4 & 3 & 2 & 11 & 5 & 8 & 3 & 6 & 10 & 0 & 0 & 7 & 9 & 0 & 5 & 11 \\
\hline \multirow{5}{*}{$\underset{\Delta}{\breve{v}}$} & Back are & 9 & 6 & 1 & 3 & 12 & 1 & 6 & 8 & 2 & 4 & 10 & 2 & 3 & 10 & 3 & 3 & 10 & 3 \\
\hline & Shoulder & 3 & 6 & 7 & 1 & 8 & 7 & 2 & 8 & 6 & 2 & 5 & 9 & 2 & 8 & 6 & 3 & 7 & 6 \\
\hline & \begin{tabular}{|l|} 
Sleeve \\
\end{tabular} & 6 & 9 & 1 & 3 & 8 & 5 & 5 & 7 & 4 & 4 & 7 & 5 & 2 & 10 & 4 & 1 & 8 & 7 \\
\hline & \begin{tabular}{|l|} 
Collar \\
\end{tabular} & 0 & 5 & 11 & 0 & 2 & 14 & 0 & 4 & 12 & 1 & 2 & 13 & 9 & 2 & 5 & 5 & 8 & 3 \\
\hline & Bottom edge & 1 & 11 & 4 & 7 & 6 & 3 & 2 & 11 & 3 & 3 & 9 & 4 & 1 & 7 & 8 & 0 & 6 & 10 \\
\hline \multirow{4}{*}{ 留 } & Sleeve and shoulder & 5 & 8 & 3 & 5 & 7 & 4 & 5 & 8 & 3 & 2 & 8 & 6 & 2 & 7 & 7 & 0 & 9 & 7 \\
\hline & Collar & 3 & 4 & 9 & 0 & 7 & 9 & 3 & 2 & 11 & 1 & 5 & 10 & 7 & 5 & 4 & 6 & 5 & 5 \\
\hline & Hips & 0 & 7 & 9 & 1 & 5 & 10 & 3 & 9 & 4 & 4 & 9 & 3 & 1 & 7 & 8 & 0 & 10 & 6 \\
\hline & Bottom edge & 9 & 6 & 1 & 8 & 6 & 2 & 10 & 5 & 1 & 11 & 4 & 1 & 5 & 6 & 5 & 4 & 8 & 4 \\
\hline
\end{tabular}

Tab. 6. Assessment of fit for individual areas of jackets prototype on the scanned body model 


\begin{tabular}{|c|c|c|c|c|c|c|c|c|c|c|c|c|c|c|c|c|c|c|c|}
\hline \multirow{3}{*}{\multicolumn{2}{|c|}{ Evaluation area }} & \multirow{2}{*}{\multicolumn{3}{|c|}{$\begin{array}{c}\text { Jacket NIKA-1Z } \\
\text { Grade }\end{array}$}} & \multirow{2}{*}{\multicolumn{3}{|c|}{\begin{tabular}{|c|} 
Jacket NIKA-1Č \\
Grade
\end{tabular}}} & \multirow{2}{*}{\multicolumn{3}{|c|}{\begin{tabular}{|c|} 
Jacket LIDA-2M \\
Grade \\
\end{tabular}}} & \multirow{2}{*}{\multicolumn{3}{|c|}{$\begin{array}{c}\text { Jacket LIDA-2Č } \\
\text { Grade }\end{array}$}} & \multirow{2}{*}{\multicolumn{3}{|c|}{$\begin{array}{c}\text { Jacket MIA-4B } \\
\text { Grade }\end{array}$}} & \multirow{2}{*}{\multicolumn{3}{|c|}{$\begin{array}{c}\text { Jacket MIA-4M } \\
\text { Grade }\end{array}$}} \\
\hline & & & & & & & & & & & & & & & & & & & \\
\hline & & -1 & 0 & 1 & -1 & 0 & 1 & -1 & 0 & 1 & -1 & 0 & 1 & -1 & 0 & 1 & -1 & 0 & 1 \\
\hline \multirow{5}{*}{ 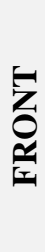 } & Bust area & 1 & 8 & 7 & 1 & 6 & 9 & 0 & 2 & 14 & 0 & 2 & 14 & 0 & 2 & 14 & 0 & 2 & 14 \\
\hline & Shoulder & 1 & 6 & 9 & 1 & 1 & 14 & 1 & 2 & 13 & 0 & 4 & 12 & 0 & 1 & 15 & 1 & 1 & 14 \\
\hline & Sleeve & 1 & 1 & 14 & 2 & 3 & 11 & 3 & 4 & 9 & 3 & 6 & 7 & 0 & 2 & 14 & 1 & 3 & 12 \\
\hline & Collar and lapel & 6 & 2 & 8 & 7 & 4 & 5 & 0 & 2 & 14 & 0 & 1 & 15 & 1 & 2 & 13 & 0 & 2 & 14 \\
\hline & Bottom edge & 3 & 8 & 5 & 4 & 7 & 5 & 4 & 7 & 5 & 2 & 9 & 5 & 0 & 2 & 14 & 0 & 3 & 13 \\
\hline \multirow{5}{*}{ 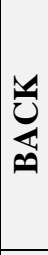 } & Back area & 0 & 7 & 9 & 0 & 5 & 11 & 0 & 5 & 11 & 1 & 5 & 10 & 1 & 8 & 7 & 0 & 9 & 7 \\
\hline & Shoulder & 1 & 1 & 14 & 1 & 1 & 14 & 1 & 1 & 14 & 1 & 0 & 15 & 1 & 3 & 12 & 1 & 0 & 15 \\
\hline & Sleeve & 1 & 6 & 9 & 1 & 6 & 9 & 3 & 2 & 11 & 3 & 3 & 10 & 1 & 5 & 10 & 0 & 4 & 12 \\
\hline & Collar & 1 & 0 & 15 & 1 & 1 & 14 & 0 & 0 & 16 & 0 & 1 & 15 & 2 & 5 & 9 & 0 & 0 & 16 \\
\hline & Bottom edge & 0 & 1 & 15 & 0 & 4 & 12 & 0 & 4 & 12 & 0 & 3 & 13 & 3 & 10 & 3 & 0 & 4 & 12 \\
\hline \multirow{4}{*}{ 椞 } & Sleeve and shoulder & 0 & 0 & 16 & 1 & 6 & 9 & 1 & 4 & 11 & 0 & 2 & 14 & 0 & 3 & 13 & 1 & 3 & 12 \\
\hline & Collar & 6 & 3 & 7 & 6 & 3 & 7 & 0 & 6 & 10 & 0 & 2 & 14 & 1 & 2 & 13 & 2 & 4 & 10 \\
\hline & Hips & 1 & 7 & 8 & 1 & 10 & 5 & 0 & 7 & 9 & 0 & 8 & 8 & 1 & 9 & 6 & 0 & 10 & 6 \\
\hline & Bottom edge & 2 & 10 & 4 & 3 & 9 & 4 & 2 & 4 & 10 & 4 & 6 & 6 & 6 & 9 & 1 & 6 & 4 & 6 \\
\hline
\end{tabular}

Tab. 7. Assessment of fit for individual areas of jackets prototype to the parametric body model

\section{Fit of jackets' prototypes to the real body model}

Real prototypes of jackets got grades for all assessment criteria: good, satisfactory and inadequate fit, Tab. 5. In most cases the evaluators assessed the collar and lapels of all jackets with grade 'good fit'. The most frequent grade 'satisfactory fit' was given for jackets fit to the body figure on the front and back side as well as for sleeves. Grade 'inadequate fit' was given to prototypes Mia-4B and Mia- 4M for the bust area on the front part and on the back part and for the sleeve. It is supposed that high stiffness and wrinkling of fabrics influenced this grade.

\section{Fit of the jackets' prototypes to the scanned 3D body model}

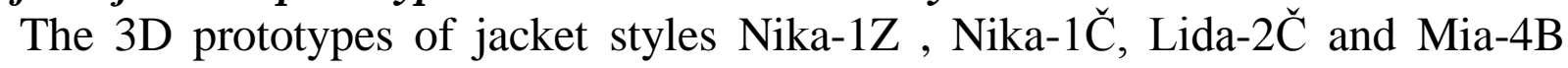
were repeatedly assessed with prevailing grade 'good fit', Tab. 6. The jacket prototype Lida-2M has got a predominant number of grades 'satisfactory fit' for nine evaluation areas, for four evaluation areas grade 'good fit', while the jacket prototype Mia-4M has got a predominant number of grades 'satisfactory fit' for seven evaluation areas and for six evaluation areas grade 'good fit'. The grade 'inadequate fit' was found for the evaluation area bottom edge from the side view, probably because of the uneven length of the jacket from the front and back side. In most cases jackets prototypes Nika and Lida were evaluated with grade 'good fit' for the collar and lapels (same grade was given also for real jacket prototype). Jackets Mia- 4B and Mia- 4M were evaluated with a predominant number of grades 'inadequate fit' for the collar from the back and side view due to imperfect jackets simulation. From the front view the prototype Mia got grade 'good fit' for all five evaluation areas.

In general, very similar estimation of the fit for the particular jackets' styles was found. Namely, the same fabric in two colours was used for one style. Therefore, it can be concluded that differences in the jackets' fit to the scanned body model depend on the construction of the jacket and characteristics of the body model. 


\section{Fit of the jackets' prototypes to the virtual parametric 3D body model}

The fit of all 3D jackets' prototypes to the parametric body model was evaluated with grade 'good fit', Tab. 7. In the most cases respondents assessed the bottom edge in the front view with grade 'satisfactory fit'. The bottom edge of the jackets' styles Nika and Lida was slightly more turbulent due to the sewn pockets. The jacket style Mia was evaluated with prevailing grade 'good fit' for all evaluation areas on the front side of the jacket, while the prevailing grade 'satisfactory fit' received the back area of a jacket for both applied fabrics. The side view on hips and bottom edge of the jackets was estimated with prevailing grade 'satisfactory fit' for all styles with the exception of the style Lida-2M.

In general, it was found that respondents evaluated with grade 'good fit' all jackets' styles on the parametric body model. The reason for this is that parametric body model is symmetrical and perfect, while the scanned and real body models have a real body posture and other body contours. Therefore, the fit of jackets and apparel look were good. However, the simulation is not completely comparable with a real body model.

5.3 Assessment of the influence of the mechanical properties of the used materials on jackets' fit

The fit of 3D jackets' prototypes to the body model depends on characteristics of the textile material and jackets' pattern design for all styles of jackets. Influence of the real measured mechanical properties on jackets' fit was also evaluated, Tab. 8.

\begin{tabular}{|l|c|c|c|}
\hline \multirow{2}{*}{ Jackets styles } & \multicolumn{3}{|c|}{$\begin{array}{c}\text { Influence of fabrics' mechanical } \\
\text { properties on fit of jackets }\end{array}$} \\
\cline { 2 - 4 } & \multicolumn{3}{|c|}{ Grade } \\
\cline { 2 - 4 } & $\mathbf{1}$ & $\mathbf{0}$ & $\mathbf{- 1}$ \\
\hline Jacket NIKA-1Z & 10 & 4 & - \\
\hline Jacket NIKA-1Č & 8 & 4 & 2 \\
\hline Jacket LIDA-2M & 14 & - & - \\
\hline Jacket LIDA-2C & 13 & 1 & - \\
\hline Jacket MIA-4B & 9 & 5 & - \\
\hline Jacket MIA-4M & 12 & 2 & - \\
\hline
\end{tabular}

Tab. 8. Influence of the measured mechanical properties of fabrics on 3D jackets' fit

It was found that successful virtual simulation of the jackets' prototypes could be achieved only by measuring the mechanical properties of textiles (fabrics and fused panels) and the fused and non-fused jacket's pattern pieces should be determined by measured mechanical properties when performing garment simulation.

3D prototypes of jackets' styles Lida-2M, Lida-2 $\breve{C}$ and Mia-4M that were simulated based on measured properties of fabrics and fused panels mostly received grade 'good fit', Tab. 8.

$3 \mathrm{D}$ prototype of the jacket style Nika-1 $\check{C}$ was assessed twice by grade 'inadequate fit', Tab. 8. The reason for this could be uncompleted simulation. Namely, folding of the lapels during the simulation was not performed completely. 
3D prototype of the jacket style Mia-4B was evaluated worst, Tab. 8. It received five times grade 'satisfactory fit'. The resulting assessment corresponds with measured properties of the fabric and fused panel, showing high bending and shear rigidity.

Based on this research it was discovered that defining the properties of the textile materials for virtual simulation and individual pattern pieces, respectively, is necessary for efficient and accurate fabric's mechanical simulation model and realistic appearance of the virtual prototype of garments.

\section{Conclusions}

Virtual cloth simulation received significant attention in the past decade, and the fashion industry has been attracted to use this newly available tool in actual product development process to strengthen the collaboration along the supply chain and shorten the product time to market.

Based on the results from this and other studies it can be concluded that virtual prototyping is definitely the future of clothing manufacturers. Its application depends not only on the used computer technology, but also on the knowledge related to evaluation the of resulted garment's appearance and virtual garment fit to the virtual body model. Namely, it is necessary to avoid the subjective influence of the evaluator and the diversity in interpretation of the prepared virtual garment prototype between the designer, technologist and buyer.

The main purpose of this study was to define and evaluate different garment styles' fit to the real and virtual body models, and to use the results as a criterion for evaluating the successfulness of the performed simulations.

The following conclusions were made based on the analysis of the results of the jackets' fit to the real, 3D scanned and 3D parametric body model:

- The appearance of the real produced prototypes of jackets was satisfactory in terms of the used textile materials and body figure. Namely, jackets were produced in garment size 42 , therefore, it was not expected to completely fit the selected body model. The real model was an older woman, which non-standard body figure affected the final appearance of jackets fit. This has been proven by comparing the jackets' fit on a parametric body model with the real and scanned body model.

- The parametric body model only approximates the real body model. Namely, the adjusted dimensions of the virtual body model were proportional, therefore, did not provide satisfactory real image of the body figure and posture. Consequently, the jackets' fit on such a body is not perfectly comparable with the fit on the real body.

- The scanned body model was perfectly compatible with the real body. This confirmed also the assessment of the jackets' fit to the real and scanned 3D body models.

- Virtual prototyping of garments still cannot fully replace the conventional prototyping. There are many unresolved technical problems for simulations that are related to the parametric body figure and its presentation in a virtual environment, properties of textile materials and preparation procedures for simulation.

- The success of the simulation certainly depends on the mechanical properties of the simulated textile and the garment's pattern design. Therefore, in the future it is 
necessary to build a database with the appropriate mechanical properties of the textile materials. These should be formed into groups according to the fabric type, fabric composition, yarns density and fabric weave, as well as surface mass of the fabric. In addition, the mechanical properties of the fused panels for these fabrics should be also provided.

- The results of this study will be used for the planned forthcoming research works related to the use of scanned body models for designing, constructing and simulating the garments for different types of body figures including people with special needs.

\section{Acknowledgement}

The authors wish to express their thanks to colleagues from the Faculty of Textile Technology, University of Zagreb, Croatia, for enabling us to carry out the 3D body scanning, which resulted in the realisation of an important part of the study, described in this book chapter.

\section{References}

Allen, B.; Curless, B.\& Popovic, Z., (2003). The space of human body shapes: reconstruction and parameterization from range scans, ACM SIGGRAPH 2003, pp. 587-594

Ancutienè, K. \& Sinkevičiūtè, D. (2011). The Influence of Textile Materials Mechanical Properties upon Virtual Garment Fit. Materials Science (Medžiagotyra). Vol. 17, No. 2, pp. 160-167, ISSN 1392-1320

Ascough, J.; Bez, H. E. \& Bricis, A.M., (1996). A Simple Beam Element, Large Displacement Model for the Finite Element Simulation of Cloth Drape. Journal of The Textile Institute, Vol. 87, No. 1, pp. 152-165, ISSN 0040-5000

Baraff, D. \& Witkin, A. (1998). Large Steps in Cloth Simulation, Computer Graphics (Proc. SIGGRAPH'98), pp. 43-54, ISBN 0-89791-999-8

Breen, D. E.; House, D. H. \& Wozny, M. J., (1994). A Particle-Based Model for Simulating the Draping Behavior of Woven Cloth, Textile Research Journal, Vol. 64, No. (11), pp. 663-685, ISSN 0040-5175

Chen, B. \& Govindaraj, M., (1995). A Physically Based Model of Fabric Drape Using Flexible Shell Theory, Textile Research Journal, Vol. 65, No. 6, pp. 324-330, ISSN 0040-5175

Collier, J. R.; Collier, B. J.; O’Toole, G. \& Sargand, S. M., (1991). Drape Prediction by Means of Finite-element Analysis, Journal of The Textile Institute, Vol. 82, No. 1, pp. 96-107, ISSN 0040-5000

Cugini, U.; Bordegoni, M. \& Mana, R. (2008). The role of virtual prototyping and simulation in the fashion sector. International Journal on Interactive Design and Manufacturing, Vol. 2, pp. 33-38, ISSN 1955-2505

Dai, X.; Li, Y. \& Zhang, X., (2003). Simulation Anisotropic Woven Fabric Deformation with a New Particle Model, Textile Research Journal, Vol. 73, No. 12, pp. 1091-1099, ISSN 0040-5175 
Eberhardt, B.; Weber, A. \& Strasser, W., (1996). A Fast, Flexible, Particle-System Model for Cloth Draping, IEEE Computer Graphics \& Applications, Vol. 16, No. (5), pp. 52-59, ISSN 0272-1716

Gan, L.; Ly, N. G. \& Steven, G. P., (1995). Study of Fabric Deformation Using Nonlinear Finite Elements, Textile Research Journal, Vol. 65, No. 11, pp. 660668, ISSN 0040-5175

Gregorčič, S.; Rudolf, A. \& Abram-Zver, M. (2011). Research on woman's dress fitting designed from different construction systems. 3rd ScientificProfessional Conference Textile Science and Economy (TNP 2011), pp. 43-49, ISBN 987-86-7672-150-4, Zrenjanin, 10 - 11th November 2011, University of Novi Sad, Technical Faculty "Mihajlo Pupin", Zrenjanin, Republic of Serbia Hu, J. \& Chen, S., (2000). Numerical Drape Behavior of Circular Fabric Sheets Over Circular Pedestals, Textile Research Journal, Vol. 70, No. 7, pp. 593-603, ISSN 0040-5175

Jevšnik, S.; Stjepanović, Z. \& Celcar, D. (2009). Virtual clothes' simulations. 1st International Conference I Love Inter/National Fashion, Jevšnik, S.(Ed.), Matičič, N. (Ed.), Šterman, S. (Ed.), pp. 67-74, Ljubljana, Slovenia, April 2-4, 2009, Academy of Design, Ljubljana

Ji1, F.; Li, R. \& Qiu, Y. (2006). Three-dimensional Garment Simulation Based on a Mass-Spring System. Textile Research Journal, Vol. 76, No. 1, pp. 12-17, ISSN 0040-5175

Lafleur, B.; Thalmann, N. M. \& Thalmann, D., (1991). Cloth Animation with Selfcollision Detection, IFIP conference on Modeling in Computer Graphics, pp. $179-187$

Lee, J.; Nam, Y.; Cui, M. H.; Choi, K. M. \& Choi, Y. L. (2007). Fit Evaluation of 3D Virtual Garment, Usability and Internationalization. HCI and Culture, Lecture Notes in Computer Science, Vol. 4559, pp. 550-558, ISBN 978-3-540-73286-0 Liu, Y. J.; Zhang, D. L. \& Yuen M. M. F., (2010). A survey on CAD methods in 3D garment design, Computers in Industry, Vol. 61, pp. 576-593, ISSN 0166-3615 Luible, C. \& Magnenat-Thalmann, N., (2007). Suitability of standard fabric characterisation experiments for the use in virtual simulations. Proceedings of World Textile Conference AUTEX 2007 Tampere, 26 - 28 June 2007, pp. 1-5 (CD version).

Magnenat-Thalmann N. \& Volino, P. (2005). From early draping to haute couture models: 20 years of research. The Visual Computer, 2005, Vol. 21, pp. 506519, ISSN 0178-2789

Magnenat-Thalmann, N. \& Thalmann, D. (2005). Virtual humans: thirty years of research, what next?, The Visual Computer, Vol. 21, No. 12, pp. 997-1015, ISSN 0178-2789

Pilar, T. (2012). Development of 3D Prototypes of Women's Clothing, Master Thesis, University of Maribor, Maribor, Slovenia

Provot, X., (1995). Deformation Constraints in a Mass-Spring Model to Describe Rigid Cloth Behavior, In proceeding Graphics Interface, pp. 147-154

Rudolf, A.; Jevšnik, S.; Stjepanović, Z. \& Pilar, T., (2008). Comparison between virtual and real shape of garments. 8th AUTEX Conference, pp. 226, 24-26 June 2008, Biella, Italy 
Rudolf, A.; Jevšnik, S.; Cupar, A.; Pogačar, V. \& Stjepanović, Z. (2010). Development of a competitive 3D ski-jumper suit prototype. $2^{\text {nd }}$ International Joint Conference on Environmental and Light Industry Technologies, pp. 401410, ISBN 978-615-5018-23-7, Budapest, Hungary, 18-19 ${ }^{\text {th }}$ of November 2010, Óbuda University, Sándor Rejtő Faculty of Light Industry and Environmental Engineering, Budapest

Rudolf, A.; Jevšnik, S. \& Stjepanovič, Z. (2012). Influence of Knitted Fabric's Stretch on Virtual Prototyping of the Underwear, Proceedings of 14th Romanian Textiles and Leather Conference, $46^{\text {th }}$ International Federation of Knitting Technologists Congress, Dodu A. (Ed.), Blaga M. (Ed.), pp.946-953, ISSN: 2285-5378, ISSN-L: 2285-5378, Sinaia, Romania, 6-8 September 2012

Stjepanović, Z.; Rudolf, A.; Jevšnik, S.; Cupar, A.; Pogačar, V. \& Geršak, J. (2010): Reconstruction of 3D body scan model for virtual garment prototyping. International Symposium in Knitting and Apparel - ISKA 2010 Iasi, ch. 4.5, November 2010, Technical University Iasi

Stjepanović, Z.; Rudolf, A.; Jevšnik, S.; Cupar, A.; Pogačar, V. \& Geršak, J. (2011). 3D virtual prototyping of a ski jumpsuit based on a reconstructed body scan model. Buletinul Institutului Politehnic din Iaşi. Secţia Textile, Pielärie, Vol. 57, No. 61, pp. 17-30, ISSN 0253-1119, Pielärie

Stjepanović, Z.; Pilar, T.; Rudolf, A. \& Jevšnik, S (2012). 3D Virtual prototyping of clothing products, Innovations in clothing technology \& measurement techniques, Bartkowiak G., Frydrych I., Pawlowa M. (Eds.), pp. 28-41, ISBN 978-83-7283-492-8, Warshaw 2012, Technical University of Lodz Press

Terzopoulos, D.; Platt, J.; Barr. A. \& Fleischer, K., (1987). Elastically Deformable Models, Computer Graphics, Vol. 21, No, 4, pp. 205-214, ISBN 978-953-510455-1

Volino, P. \& Thalmann, N. M.(1994). Efficient Self-Collision Detection on Smoothly Discretized Surface Animation Using Geometrical Shape Regularity, Proceedings EUROGRAPHICS'94, Vol. 13, No. (3), pp. 155-166, ISBN 159593-564-9

Volino, P.; Cordier, F. \& Magnenat-Thalmann, N. (2005). From early virtual garment to interactive fashion design. Computer Aided Design, Vol. 37, pp. 593-08, ISSN 00104485

Weil, J. (1986). The Synthesis of Cloth Objects, Computer Graphics, Proceedings of SIGGRAPH 86, Evans D.C, Athay R. J. (Eds.): Vol. 20, No. 4, pp. 49-54, ISBN 0-89791-166-0, Dallas, Texas

Wu, Y.Y.; Mok, P.Y.; Kwok, Y.L.; Fan, J.T. \& Xin, J. H. (2011). An investigation on the validity of $3 \mathrm{D}$ clothing simulation for garment fit evaluation. Proceedings of the IMProVe 2011, International conference on Innovative Methods in Product Design, pp. 463-468, June $15^{\text {th }}-17^{\text {th }}$, Venice, Italy

Yang, Y. \& Thalmann, N. M., (1993). An Improved Algorithm for Collision Detection in Cloth Animation with Human Body, Computer Graphics and Applications (Pacific Graphics proceedings 1993), pp. 237-251, Seoul, Korea

$\mathrm{Yu}, \mathrm{W}$. (2004). Subjective assessment of clothing fit. Clothing appearance and fit: Science and Technology, Woodhead Publishing Limited, ISBN 1-85573-745-0, Cambridge, England 